\title{
CONSIDERACIONES EN TORNO AL RECURSO DE INTERPRETACIÓN CONSTITUCIONAL
}

POR

\author{
ANGELA FIGUERUELO \\ Universidad de Salamanca
}

En el momento actual el concepto de Estado de Derecho no es únicamente una construcción teórica formulada por los juristas, sino que ha pasado a formar parte del Derecho Constitucional positivo de forma patente y expresa. Su significado debe ser determinado en cada caso en el marco de la Constitución en que se halla inserto, sin perjuicio de la validez que puedan tener sus definiciones abstractas $^{1}$.

En el marco teórico previamente descrito la Constitución ha de ser entendida como norma fundamental positiva que vincula a todos los poderes públicos, incluido el Parlamento, por lo que la ley no puede ser contraria a los preceptos constitucionales ni a los principios y valores que le sirven de base y a cuya realización se aspira. Esta es la esencia del Estado Constitucional de Derecho, entendido como perfeccionamiento del mero Estado legal de Derecho ${ }^{2}$.

Pero, la primacía de la Constitución sería jurídicamente imperfecta si careciese de garantía jurisdiccional, es decir, si la constitucionalidad de las decisiones y actos de los poderes públicos no son enjuiciables por órganos distintos de

${ }^{1}$ Cfr. LeiBHOlZ: «Der status des Bundesverfassungsgerichts» publicado en el Jahrbuch des Oeffentlichen Rechts, Neue Folge. Vol. VI.

2 Cfr. K. Stern: Das Staatsrecht des Bundesrepublik Deutschand, Munich, 1977, Vol. I págs. 955 y ss. 
aquellos que son sus autores. Por ello se ha dicho, con razón, que la jurisdicción constitucional es la garantía institucional básica del Estado Constitucional de Derecho porque asegura y perfecciona su funcionamiento ${ }^{3}$.

Ahora bien, cuando se trata de saber cuáles deben ser los órganos encargados de conocer jurisdiccionalmente de las normas constitucionales, encontramos diferencias de unos órdenes constitucionales a otros según los criterios de funcionalidad que los inspiran. Aquí, como en tantos otros temas no hay soluciones de validez general, ya que, en principio, todas ellas pueden ser compatibles con el Estado Constitucional de Derecho ${ }^{4}$.

En el sentido de lo anteriormente expuesto, la Constitución de la República Bolivariana de Venezuela de 30 de diciembre de 1999, en su artículo 7, reconoció el carácter de dicha Constitución como norma suprema ${ }^{5}$ prescribiendo lo siguiente:

«La Constitución es la norma suprema y fundamento del ordenamiento jurídico. Todas las personas y los órganos que ejercen el Poder Público están sujetos a esta Constitución»

A su vez, en el Artículo 2, se procede a la definición teórica de la forma de Estado de la República Bolivariana de Venezuela y a los valores que informan en el sentido siguiente:

«Venezuela se constituye en un Estado democrático y social de Derecho y de justicia, que propugna como valores superiores de su ordenamiento jurídico y de su actuación, la vida, la libertad, la justicia, la igualdad, la solidaridad, la democracia, la responsabilidad social y, en general, la preeminencia de los derechos humanos, la ética y el pluralismo político».

3 Cfr. K. Stern: Das Staatsrecht..., pág. 657 y ss. También M. GarCía Pelayo: «El «status» del Tribunal Constitucional», en Revista Española de Derecho Constitucional no 1 . Madrid, 1981, págs. 11 y ss.

${ }^{4}$ Cfr. al respecto, entre otros: L. Pegoraro, Lineamenti di giustizia costituzionale comparata, G. Giappichelli Editore, Turín, 1998. L. FAVOREAU: Los tribunales constitucionales, Ariel, Barcelona, 1994. N. GONZÁleZ-Deleito DOMINGO: Tribunales Constitucionales, organización y funcionamiento, Tecnos, Madrid, 1980. J. Almagro Nosete: Justicia Constitucional (Comentarios a la Ley Orgánica del Tribunal Constitucional), Madrid, 1980. K. STERN: Das Staatsrecht..., pág. 936 y ss.

5 Sobre este concepto y sus implicaciones jurídicas consúltese la, ya clásica, obra de E. GARCÍA DE EnTERRÍA: La Constitución como norma y el Tribunal Constitucional, Civitas, Madrid, 1981. También de F. Rubio LlORENTE: «La Constitución como fuente del Derecho» en la obra recopiladora La Forma del Poder, C.E.C. Madrid, 1993. En el mismo sentido M. ARAGÓN REYES: «La eficacia jurídica de la Constitución» en la obra recopiladora Escritos de Derecho Constitucional C.E.P.C., Madrid 1998. 
Las medidas legislativas, gubernamentales y administrativas tomadas en función de los dictados de los preceptos constitucionales darán vigencia y desarrollo al postulado del Estado social. La Asamblea Nacional, elegida por sufragio universal, es la máxima expresión institucional del postulado del Estado democrático, mientras que, el Poder judicial y los correspondientes órganos que conforman el sistema de justicia harán realidad el postulado del Estado de justicia. Todo ello sin perder de vista el amplio elenco de valores superiores que impregnan todo el ordenamiento constitucional y que deben estar presentes -en cuanto mandatos al legislador y al intérprete- en todas las actuaciones de los poderes públicos.

Falta aludir a la culminación del Estado de Derecho tal y como fue ideado y configurado por el constituyente venezolano que, elaborando una Constitución con vocación de auténtica, tuvo que prever los mecanismos necesarios para transformar la supremacía en supralegalidad constitucional ${ }^{6}$ y para ello establecer los medios jurídicos al efecto: se creó una Sala Constitucional en el Tribunal Supremo de Justicia con el objetivo de que ejerza la jurisdicción constitucional, al mismo tiempo que se consagraron de forma expresa los principios fundamentales sobre los que descansa la justicia constitucional en el mundo 7 .

\section{I}

El vigente texto constitucional venezolano sienta las bases, por primera vez en el constitucionalismo de este país, para el trazado de un sistema de justicia constitucional $^{8}$. Aunque se pudo haber optado por un modelo diferente (ya que

${ }^{6}$ Consúltese, al respecto, M. ARAGÓN REYES: Sobre las nociones de supremacía y supralegalidad constitucional, Universidad Externado de Colombia, Bogotá, 1986.

7 Cfr. J.V. Haro G.: La justicia constitucional en Venezuela y la Constitución de 1999, págs. 135 y ss. El autor destaca que "varios elementos de ese sistema (de justicia constitucional) pueden ser objeto de críticas y (ello) nos permite concluir forzosamente que si bien el resultado final representa una evidente evolución para la justicia constitucional en Venezuela, existen fundamentos y normas de ese sistema que son perfectibles y que pueden ser objeto de un grado de evolución mayor».

${ }^{8}$ A pesar de ello, algún sector de la doctrina destacada ha puesto de manifiesto que en Venezuela «en ninguna época, ni presente ni pretérita hemos tenido verdadera jurisdicción constitucional»... puesto que, aunque el sistema venezolano haya sido denominado como «control integral de constitucionalidad» por haber hecho coexistir el control concentrado con el difuso y con el control preventivo, no se han dado los elementos imprescindibles para que exista una verdadera jurisdicción constitucional. A saber: 
hubo propuestas ${ }^{9}$ para crear un Tribunal Constitucional como órgano jurisdiccional, autónomo e independiente de los poderes públicos que ejerciese la función de máximo intérprete de la Constitución) razones históricas y de oportunidad política hicieron prevalecer por consenso la tesis de crear una Sala Constitucional en el Tribunal Supremo de Justicia.

Personalmente, somos de la opinión de que la función que las modernas constituciones normativas encomiendan a los órganos encargados de ser sus máximos intérpretes (comisionados del poder constituyente) para controlar que las actuaciones de los poderes constituidos se enmarquen dentro de los dictados de las normas constitucionales, es más propia de un órgano especializado, situado al margen de los poderes que debe controlar, para evitar, en lo posible, ser juez y parte en muchas de sus actuaciones.

No obstante, como no hay soluciones de validez general para este tema en concreto, conviene resaltar que la creación de una Sala Constitucional resulta un avance respecto a la Constitución de 1961 porque dota, por primera vez, al sistema político venezolano de un órgano especializado (aunque formando parte de la cúpula del poder judicial) encargado de velar porque el carácter de la Constitución como norma suprema sea una realidad «de facto» gracias a su jurisprudencia en el ejercicio de su función de máximo y último intérprete constitucional.

La Constitución Venezolana de 1999 a la hora de regular la justicia constitucional (en cuanto conjunto de garantías encaminadas a conseguir la supremacía de la Ley Fundamental) ha hecho coincidir en su articulado el modelo di-

1/ un órgano judicial especializado para conocer exclusivamente del contencioso constitucional.

2/ que las decisiones que ese órgano pronuncie sobre la incompatibilidad de las normas legales o de igual rango con el texto constitucional produzcan su eliminación del ordenamiento positivo con efectos generales y obligatorios.

3/ que exista una adecuada articulación entre los diferentes mecanismos de control constitucional y sus operadores y el máximo órgano judicial de control.

Cfr. J. CALCAÑo de TEMELTAS: «La jurisdicción constitucional en Venezuela: Pasado, presente y futuro", en Revista de Derecho Constitucional, no 2, Caracas 2000, págs 61 y ss.

9 En este sentido la propuesta de J.V. HARO ante la Comisión Constitucional de la Asamblea Nacional Constituyente presentada en el mes de agosto de 1999. También la propuesta de J. CALCAÑO DE TEMELTAS presentada en el mes de septiembre de ese año ante la misma Comisión. Esas propuestas no fueron acogidas por la Comisión Constitucional ya que, en palabras del constituyente Sr. A. BREWER CARÍAS «no consideramos conveniente, en este momento, pensar en una Corte o Tribunal Constitucional separado de la Corte Suprema de Justicia para constituir la jurisdicción constitucional». Cfr. J.V. HARO «La justicia constitucional en Venezuela y la necesidad de un Tribunal Federal Constitucional (Una propuesta para la Asamblea Nacional Constituyente)», Revista de Derecho Administrativo, no 6, Caracas, 1999. Del mismo autor: "La justicia constitucional en Venezuela...» op. cit., págs. 135 y ss. 
fuso ${ }^{10}$, de influencia norteamericana, con el sistema concentrado de ascendente europeo. De esta forma el artículo 334 de la Constitución señala que: «Todos los jueces y juezas de la República, en el ámbito de sus competencias y conforme a lo previsto en esta Constitución y en la ley, están en la obligación de asegurar la integridad de esta Constitución.

En caso de incompatibilidad entre esta Constitución y una ley u otra norma jurídica, se aplicarán las disposiciones constitucionales, correspondiendo a los tribunales en cualquier causa, aún de oficio, decidir lo conducente.

Corresponde exclusivamente a la Sala Constitucional del Tribunal Supremo de Justicia, como jurisdicción constitucional, declarar la nulidad de las leyes y demás actos de los órganos que ejercen el Poder Público dictados en ejecución directa e inmediata de esta Constitución o que tengan rango de ley, cuando colidan con aquella».

De este precepto se desprende claramente la capacidad, que por mandato constitucional, tienen los jueces ordinarios en el ejercicio de sus funciones de dejar de aplicar una norma, cuyo contenido choque con los preceptos constitucionales, y aplicar en su lugar la Constitución cuyo rango en el sistema de fuentes es superior. Su función no puede ir más allá — como le corresponde por naturaleza a todo sistema de control difuso de constitucionalidad de la ley- y la norma en cuestión sigue estando plenamente vigente en el ordenamiento jurídico venezolano. Dejará de estarlo cuando la Sala Constitucional del Tribunal Supremo, en el ejercicio del monopolio de rechazo de las normas subordinadas a la Constitución que contraríen su contenido las declare nulas.

En el sentido previamente resaltado conviene citar el Art. 336 de la Constitución donde con carácter de generosa amplitud el constituyente fijó las competencias de la Sala Constitución al Tribunal Supremo de entre las que, a los efectos de este trabajo, merecen destacar los cuatro primeros apartados que hacen referencia a la facultad que dicho órgano tiene para declarar la nulidad total o parcial de normas y actos con rango de ley directamente sometidos a la Constitución y que choquen con ella.

${ }^{10}$ Dicho control difuso existe en Venezuela desde el siglo XIX siendo regulado en la legislación ordinaria. Así, en el Art. 20 del Código de Procedimiento civil que, al respecto señala:

«Cuando la ley vigente, cuya aplicación se pida, colidiere con alguna disposición constitucional, los jueces aplicarán éste con preferencia»

A su vez el Art. 19 del Código Orgánico Procesal Penal, posteriormente, estableció:

Control de la constitucionalidad. Corresponde a los jueces velar por la incolumidad de la Constitución de la República. Cuando la ley cuya aplicación se pida colidiere con ella, los tribunales deberán atenerse a la norma constitucional»

Cfr. A. R. BreWer Carías: Instituciones políticas y constitucionales, Tomo VI, La Justicia Constitucional, Caracas 1997, págs. 86 y ss. 
Entendemos que este precepto viene a completar el contenido del Art. 335 en su segundo apartado donde, de forma expresa, se dice: «Las interpretaciones que establezca la Sala Constitucional sobre el contenido o alcance de las normas y principios constitucionales son vinculantes para las otras Salas del Tribunal Supremo de Justicia y demás tribunales de la República».

La obligatoriedad de las interpretaciones de la Sala Constitucional en el ejercicio de las funciones que le han sido atribuidas (Art. 336) se deriva de su naturaleza de último - aunque no único- intérprete de la Constitución. Es decir, siguiendo el imperativo kantiano, la Sala Constitucional, aunque no es un Tribunal Constitucional, funciona "como si» lo fuera en el ejercicio del control concentrado de la constitucionalidad y sirve de punto de obligado encuentro con el control difuso de la misma que se ejerce por todos los jueces y tribunales de la República y, por supuesto por el resto de las Salas del Tribunal Supremo, cumpliendo así el mandato del Art. 266. A que prescribe:

Son atribuciones del Tribunal Supremo de Justicia:

1) Ejercer la jurisdicción constitucional conforme al Título VIII de esta Constitución.

Es en ese Título VIII dedicado a «la protección de la Constitución», donde no de forma muy clara pero si fácilmente comprensible, se aprecia la voluntad constituyente de hacer convivir el sistema de jurisdicción concentrada con el sistema difuso (configurando un sistema mixto o integral). Así las cosas, todos los jueces, incluido el Tribunal Supremo en todas sus Salas, tienen la obligatoriedad de asegurar el carácter de la Constitución como norma suprema pero, únicamente la Sala Constitucional dispone de capacidad para declarar nulas las normas con rango de ley.

A estas consideraciones llegamos, únicamente, a partir del análisis de los preceptos constitucionales reseñados y sin entrar a hacer balance del contenido aclaratorio que, sobre este tema, se hace en la «Exposición de Motivos» de la Constitución de 1999, que fue publicada el 24-03-2000 y que había sido "decretada» por la Asamblea Nacional Constituyente en su sesión de clausura, el 30-12000. Esta "Exposición de Motivos» dictada después de ser proclamada la Constitución el 20-12-99, suscita, cuando menos, serias dudas jurídicas ${ }^{11}$, porque, aunque su intención sea «aclarar e interpretar» cuestiones constitucionales,

${ }^{11}$ Cfr. también sobre este tema, entre otros A.R. BREWER CARÍAS: «Comentarios sobre la ilegítima "Exposición de Motivos» de la Constitución de 1999 relativa al sistema de Justicia Constitucional», Revista de Derecho Constitucional, no 2, Caracas 2000, págs. 47 y ss. En el mismo sentido crítico A. CÁNOVA GONZÁLEZ: «La futura justicia constitucional en Venezuela (En contra de la Exposición de motivos de la Constitución de 1999 y a favor del Anteproyecto de Ley aprobado por la Corte Suprema de Justicia)", Revista de Derecho Constitucional, n 2, Caracas, págs. 93 y ss. 
su existencia no se justifica desde la óptica constitucionalista porque, cualquier jurista opera en el convencimiento de que quien interpreta "crea" y esos actos interpretativos de la Exposición de Motivos efectuados fuera de los cauces jurídicos oportunos han llevado a modificar en algunos casos el contenido de las normas constitucionales eludiendo las funciones del "poder constituyente constituido", es decir, el poder de reformar la Constitución (regulado por la propia Constitución Bolivariana en el Título X, arts. 340 a 346) ${ }^{12}$.

Y esto es así, creemos, porque, desde la Teoría del Derecho Constitucional se entiende que, una vez redactada la Constitución y aprobada por el pueblo (que es quien tiene la última palabra al respecto) habiendo entrado ésta en vigor, el poder constituyente se "retira» ${ }^{13}$ y la soberanía "queda depositada» en la propia Constitución — que no tiene necesariamente que obedecer a los cánones de un texto literario-. El carácter de norma suprema de la misma conlleva que sus intérpretes naturales sean el juez (aplicándola) y el legislador (desarrollándola) y la custodia de esa actuación se encomienda a un órgano de control encargado de su garantía y defensa.

\section{II}

La Sala Constitucional del Tribunal Supremo de Justicia venezolano es una más de las Salas que conforman el máximo órgano del Poder Judicial en este país (art. 262 de la Constitución Bolivariana de 1999) al que le corresponde ejercer la jurisdicción constitucional conforme al Título VIII de la misma (art. 266, apd. 1). Aunque esto es muy cierto entendemos necesario hacer una matización: Todos los jueces de la República (incluidas las Salas del Tribunal Supremo) ejercen la jurisdicción constitucional en su aspecto difuso, pero únicamente la Sala Constitucional tiene facultades «ex Constitutione» para arrojar del ordenamiento jurídico normas con rango de ley, dictadas en ejecución directa e inmediata de la Constitución. Por ello, la Sala Constitucional ocupa en el marco del ordenamiento venezolano un lugar distinto al resto de las Salas del Tribunal

${ }^{12}$ Cfr. sobre este punto, la obra, ya clásica, de P. DE VEGA GARCía: La reforma constitucional y la problemática del poder constituyente, Tecnos, Madrid, 1985. También J. PÉREZ ROYO: La reforma de la Constitución, Congreso de los Diputados, Madrid 1987. Más reciente y más crítica la obra de J. L. REQUeJO PAGÉS: Las normas preconstitucionales y el mito del poder constituyente, Centro de Estudios políticos y constitucionales, Madrid, 1998.

${ }^{13}$ Cfr. M. KRIELE: Introducción a la teoría del Estado. Fundamentos históricos de la legitimidad del Estado Constitucional Democrático, Depalma, Buenos Aires 1980, especialmente las págs. $315 \mathrm{y}$ ss. 
Supremo y sus interpretaciones sobre las normas y principios constitucionales (art. 335 de la Constitución Bolivariana) vinculan al resto de los poderes públicos, incluidas las otras Salas del Tribunal Supremo. Es decir, tiene la última palabra en lo que a la interpretación constitucional se refiere.

Esa labor interpretativa la lleva a cabo ejerciendo las atribuciones que la propia Constitución le concede en el art. 336:

1) Declarar la nulidad total o parcial de las leyes nacionales y demás actos con rango de ley de la Asamblea Nacional, que colidan con esta Constitución.

2) Declarar la nulidad total o parcial de las Constituciones y leyes estatales de las ordenanzas municipales y demás actos de los cuerpos deliberantes de los Estados y Municipios dictados en ejecución directa e inmediata de esta Constitución y que colidan con ella.

3) Declarar la nulidad total o parcial de los actos con rango de ley dictados por el Ejecutivo Nacional, que colidan con esta Constitución.

4) Declarar la nulidad total o parcial de los actos en ejecución directa e inmediata de esta Constitución dictados por cualquier otro órgano estatal en ejercicio del Poder Público, cuando colidan con ella.

Sigue enumerando el precepto en cuestión competencias propias de cualquier sistema de justicia constitucional y terminan enunciando, en el apartado 11, una cláusula que como en el caso español, encierra un cierto peligro de desconstitucionalización ${ }^{14}$ de las competencias de la Sala Constitucional:

11) Las demás que establezcan esta Constitución y la ley.

En el elenco numeroso de competencias que la Constitución atribuye a la Sala constitucional no encontramos referencia alguna «al recurso o acción autónoma de interpretación constitucional». Este, aparece por primera vez en la Sentencia 1077, de fecha 22 de septiembre de 2000, dictada por la Sala Constitucional del Tribunal Supremo de Justicia.

No tenemos conocimiento de la existencia de un recurso de esta naturaleza en ninguno de los sistemas de justicia constitucional vigentes. La singularidad es tal que la Sala Constitucional ha creado «ex novo» esta competencia dotándola de una naturaleza jurídica cuestionable, de un objeto amplio y detallado, de una

${ }^{14}$ Sobre este tema conviene consultar a P. DE VEGA GARCía: «Comentario al Título IX de la CE» en la obra colectiva Constitución Española. Edición comentada, Madrid, 1979 págs. 337 y ss. donde se mantienen críticas acertadas sobre los peligros jurídicos que encierran las cláusulas en blanco recogidas en las Constituciones. 
legitimación, de unos efectos y de un procedimiento de actuación para este caso concreto.

No es ésta la única de las Sentencias al respecto pero, sí es la primera y la más importante porque el resto, dictadas posteriormente, siguen las líneas generales de la que aquí citamos. El hecho de que este tema haya suscitado nuestro interés de estudiosa del Derecho Constitucional se debe a que, sin duda, nos encontramos ante un claro ejemplo de lo que no pueden, ni deben, hacer los órganos de justicia constitucional: Excederse de los límites de sus funciones. Ya que, si actúan de esa forma están cuestionando sus posibilidades y su futuro ${ }^{15}$ como máximos intérpretes de la Constitución y, el carácter de la misma como norma suprema quedaría en entredicho arrojando serias dudas sobre la funcionalidad de todo el sistema jurídico-político. Por eso siempre que la literatura especializada sobre la justicia constitucional reflexiona sobre la función de control ejercida por los órganos encargados de ello termina acercándose al tema de sus límites. Más que por lo que dichos órganos hacen (tema sobre cuya legitimidad pueden existir dudas) la doctrina se pregunta «por la forma en que lo hacen o deben hacerlo, por la autolimitación con que actúa o debe actuar, por el cuidado que tiene o debe tener en no invadir la esfera de los demás órganos del Estado, en respetar no la discrecionalidad sino la libertad de configuración de los órganos políticos, singularmente del legislador, por lo que se considera que la Justicia Constitucional puede tener su sitio en el Estado Constitucional democrático» ${ }^{16}$.

Para la doctrina constitucionalista la cuestión de los límites de la Justicia Constitucional en cuanto "punto neurálgico» del tema es algo pacífico, aunque no se desconozca la imposibilidad de fijar tales límites con precisión, ya que «el esfuerzo de ceñir la jurisdicción constitucional a firmes límites materiales, institucionales o funcionales, casi se asemeja al intento de la cuadratura del círculo. No obstante, desistir de este intento equivaldría prácticamente a una capitulación ante los hechos y le prestaría al Tribunal un flaco servicio, porque su autoridad fáctica proviene precisamente, y no en última instancia, de la observancia de tales límites» ${ }^{17}$.

Por lo anteriormente dicho la justificación de los órganos encargados de ejercer la Jurisdicción constitucional, en cuanto institución, se basa fundamental-

15 Cfr. E. García de ENTERría: «La posición jurídica del Tribunal Constitucional en el sistema español: posibilidades y perspectivas», en La Constitución como norma y el Tribunal Constitucional, Civitas, Madrid 1981, págs 121 y ss.

${ }^{16}$ En este sentido se pronuncia J. PÉREZ ROYO: Tribunal Constitucional y división de poderes, Tecnos, Madrid, 1988, pág. 19.

${ }_{17}$ Cfr. al respecto H. P. SCHNEIDER: «Jurisdicción constitucional y separación de poderes», Revista Española de Derecho Constitucional, no 5, Madrid, 1982, pág. 38. 
mente en las características de su organización y del procedimiento con el que actúan: se trata de órganos que no pueden intervenir de oficio, sino que deben hacerlo a instancia de parte y con una legitimación para actuar ante ellos bastante limitada. Sus competencias están enumeradas y tasadas, su decisión está siempre referida a casos individuales y es por ello una decisión puntual. El procedimiento a través del cual adquieren información, la procesan y la traducen en una Sentencia limita objetivamente el alcance de su decisión, por cuanto pueden condicionar la voluntad de los demás órganos del Estado y especialmente, la del legislador de manera «negativa» pero sin poder sustituirla "positivamente» y dar solución a los problemas políticos y sociales que se plantean en la comunidad y exigen la producción de las normas ${ }^{18}$.

El aserto previamente expuesto tiene su razón de ser porque, en cualquier Estado democrático, lo más importante de la introducción de un sistema de justicia constitucional es el cambio operado en el tema de la interpretación de la Constitución. De esta forma pasamos de la existencia de una sola interpretación de la Constitución efectuada por órganos políticos (principalmente las Cámaras legislativas) mediadores entre la política y el derecho, al establecimiento de una interpretación compartida, sistema en el cual las Cámaras interpretan inicialmente la Constitución pero, esa interpretación en algunos casos puede ser sometida a la revisión de la Justicia Constitucional: se trata de un sistema de interpretación parlamentaria condicionado por la Constitución tal y como es definida de forma vinculante por el órgano encargado de ejercer el control de constitucionalidad $^{19}$.

En resumen, en todo Estado Constitucional el problema de los límites del poder político termina siendo siempre un problema de interpretación de la Constitución. Y, en aquellos casos en que el poder constituyente optó por la opción de someter al legislador a controles externos, es el órgano que ejerce la jurisdicción constitucional el que tiene que autolimitarse al interpretar la norma suprema para no transformar la prerrogativa de la interpretación de la Constitución en un monopolio de hecho y terminar así interfiriendo de forma indebida en la competencia de los otros órganos del Estado ${ }^{20}$.

18 Sobre este tema y la legitimidad del control de un órgano democrático por otro que adolece de ese carácter, al menos de forma directa, consúltese a M. CAPELLETTI: «¿Renegar de Montesquieu? La expansión y legitimidad de la justicia constitucional», REDC, $\mathrm{n}^{\circ}$ 17, págs. 36-41

19 Cfr. P. HÄBERLE: Verfassungsgerichtsbarkeit, Darmstadt, 1976, pág. 307 y ss.

${ }^{20}$ Cfr. K. Stern: Das Staatsrecht..., op. cit. pág. 84. También J. Pérez Royo, Tribunal Constitucional..., op. cit. pág. 23. 
La Sala Constitucional del Tribunal Supremo de Justicia, en la Sentencia 1077, resuelve el asunto que sometió a su consideración un ciudadano venezolano, abogado en ejercicio, que, actuando en su propio nombre, le plantea una serie de preguntas al órgano titular de la interpretación última del texto constitucional, acerca del significado y la forma de hacer valer los intereses difusos o colectivos $^{21}$.

El fundamento jurídico de esa petición es el art. 266, apd. 6 de la Constitución de 1999. En esta norma constitucional se establece un «recurso de interpretación sobre el contenido y alcance de los textos legales, en los términos contemplados en la ley». Esta competencia es una atribución expresa del Tribunal Supremo a tenor de lo preceptuado en el mismo art. 266. Las atribuciones de la Sala Constitucional se prevén en el art. 336 de la Constitución y entre ellas no se encuentra ningún recurso de interpretación de la Constitución.

Quien interpone el recurso fundamenta su solicitud en los arts. 26 y 27 de la Constitución que, respectivamente, reconocen el derecho de acceso a la justicia para hacer valer los derechos e intereses «incluso los colectivos o difusos» y, el derecho a ser amparada, que tiene toda persona, por los tribunales en el goce y ejercicio de los derechos y garantías constitucionales. Según el solicitante de la interpretación la Sala será competente para responder a sus cuestiones porque a ella le corresponde la interpretación máxima y última de la Constitución (art. 335 de la Constitución).

$\mathrm{Al}$ examinar la situación que se le plantea y, basándose en el texto Constitucional y en su Exposición de Motivos (en nuestra opinión, como ya dejamos sentado, de muy dudosa validez jurídica) la Sala Constitucional es consciente de que no le ha sido atribuida una competencia como la que se dispone a ejercitar al interpretar «in abstracto» la Constitución sin la existencia de problemas concretos que vinculen dicha interpretación. Por ello, aunque el acceso a la Sala Constitucional se efectúe únicamente con motivo de la acción popular de inconstitucionalidad, la acción de amparo, el recurso de interpretación de leyes $u$ otro caso concreto de carácter jurisdiccional cuya competencia esté atribuida a la Sala no se encuentran obstáculos para los razonamientos de la mayoría sentenciadora de la Sala Constitucional, entendiendo que en esa expresión vaga e imprecisa

${ }^{21}$ Un comentario crítico y acertado en torno a esta sentencia puede consultarse en J. V. Haro G.: «La interpretación de la Constitución y la Sentencia 1077 de la Sala Constitucional (Un comentario sobre los límites del juez constitucional)» en Revista de Derecho Constitucional, $\mathrm{n}^{\circ}$ 2, Caracas 2000, págs. 453 y ss. 
que hemos resaltado tiene cabida la «acción o recurso autónomo de interpretación Constitucional».

En la búsqueda de fundamentos que justifiquen el ejercicio de una función que le es impropia, el mejor argumento que se le ocurre a la Sala Constitucional es operar "per saltum" y entender que al igual que existe un recurso de interpretación de leyes en el art. 266 de la Constitución Bolivariana también «debería» existir un recurso de interpretación de la Constitución porque, al tenor de lo dispuesto en el art. 335 de la precitada norma a la Sala Constitucional le corresponde ejercer, con carácter vinculante, la interpretación de la Constitución.

$\mathrm{Al}$ recabar argumentos para determinar si alguien puede abrir la puerta de la legitimación para dirigirse a la Sala planteando una competencia de la que éste órgano carece, se alude reiteradamente a distintos autores y sus correspondientes doctrinas que tratan, naturalmente de cuestiones referentes a interpretación procesal en legislación ordinaria. No se puede citar la opinión de ningún constitucionalista o de alguna doctrina de derecho procesal constitucional para apoyar sus argumentos porque en este tema las opiniones están claras y no inducen a confusión. Es doctrina común que los órganos de justicia constitucional no funcionan de oficio sino a instancia de parte y con una legitimación bastante restringida. Todo lo contrario de lo que, al respecto, parece mantener la Sala al senalar que: «...cualquiera con interés jurídico actual puede solicitar la interpretación de la ley conforme a las previsiones legales, y también la interpretación de la Constitución, para así obtener una sentencia de mera certeza sobre el alcance y contenido de las normas constitucionales, acción que sería de igual naturaleza que la interpretación de la ley».

Pero como no se trata de una acción popular no lo es tampoco la de interpretación de la ley, quien intente el «recurso de interpretación constitucional sea como persona pública o privada, debe invocar un interés jurídico actual, legítimo, fundado en una situación jurídica concreta y específica en que se encuentra y que requiere necesariamente de la interpretación de normas constitucionales aplicables a la situación, a fin de que cese la incertidumbre que impide el desarrollo y efectos de dicha situación jurídica. En fin, es necesario que exista un interés legítimo que se manifiesta por no poder disfrutar correctamente la situación jurídica en que se encuentra, debido a la incertidumbre, en la duda generalizada».

También es consciente la Sala Constitucional, y así lo manifiesta, de la inexistencia de un procedimiento para tramitar este recurso inexistente. Ni la vigente Constitución ni la Ley Orgánica de la Corte Suprema de Justicia pueden contemplar nada al respecto, por ello manda al legislador ordinario que defina este procedimiento en la nueva Ley Orgánica del Tribunal Supremo de Justicia 
y mientras tanto, tratándose de un asunto de mero derecho, que no requiere la instrucción de hechos, no considera necesario la Sala aplicarle el artículo 102 de la Ley Orgánica de la Corte Suprema de Justicia, remitiéndose a uno de los procedimientos existentes en dicha ley, para ventilar las diversas demandas que ella contiene.

Por lo tanto, presentando el recurso, en el cual se indica su objeto, con indicación de las normas y principios sobre los que se pide la interpretación sobre su contenido y alcance, la Sala admitirá o no, y en caso de que lo admita, en aras a la participación de la Sociedad, si lo creyese necesario emplazará por edicto a cualquier interesado...

Es decir que aunque la Sentencia de la Sala Constitucional contiene un mandato al legislador futuro para que desarrolle el procedimiento a seguir nos encontramos que en su pronunciamiento, de forma detallada, desarrolla un procedimiento para su propia actuación, que comprende desde el planteamiento del recurso hasta que se dicte la correspondiente sentencia.

En el caso que nos ocupa, como en el resto de los fallos de otras sentencias recaídas sobre un asunto de esta naturaleza, el fallo declara inadmisible el recurso porque «lo pedido se refiere a situaciones que ya fueron resueltas en fallo de fecha 30 de junio de 2000 (Defensoría del Pueblo) sin que lo allí expresado sufra cambios para esta fecha».

Este es el motivo que impide que podamos analizar, de momento, el significado y alcance de una interpretación de amplio espectro que puede ser efectuada «in abstracto», con efectos «erga omnes» por el máximo y último intérprete de la Constitución (art. 335 de la Constitución Bolivariana).

Termina la Sentencia con el voto concurrente ${ }^{22}$ de uno de los Magistrados de la Sala que, aunque participa del fallo, discrepa de los motivos que sustentan la decisión de la Sala de crear una nueva competencia sustituyendo las funciones del poder constituyente o del legislador ordinario (art. 336, apd. 11). Nos parecen acertadas todas sus observaciones en las que, con sólidos fundamentos jurídicos, pone de manifiesto lo impropio de la interpretación abstracta de la Constitución por los operadores jurídicos y el talante académico de las argumentaciones del órgano sentenciador que dan la impresión de hallarnos ante un «dictamen jurídico» y no ante una Sentencia de un tribunal de justicia. También se rechaza que, por analogía, la naturaleza jurídica del recurso de interpretación de leyes (existente en el ordenamiento jurídico venezolano) le permita a la Sala

22 Sobre el significado del voto disidente, consúltese, entre otros a F. J. EZQUIAGA: El voto particular, Marcial Pons, Madrid, 1990. También J.L. CASCAJO CASTRO: «La figura del voto particular en la jurisdicción constitucional española», en REDC, nº 17, Madrid 1986. 
crear uno semejante en el orden constitucional subvirtiendo el sistema de fuentes del derecho ${ }^{23}$ y poniendo en peligro el funcionamiento de todo el sistema creado por la Constitución. Este, sin duda, será uno de los riesgos mayores de la declaratoria de la sentencia comentada, al margen de otros, de menor calado, pero también relevantes que se exponen en el voto concurrente.

\section{IV}

Un comentario jurisprudencial de las características del presente no puede entrar a desarrollar a fondo los problemas principales que de lo comentado se derivan; por ello, únicamente pretendemos dejarlos esbozados:

1) ¿Dónde están los límites a la actuación del último intérprete de la Constitución?

2) Complejidad de los problemas de la interpretación de la Constitución

A/ En la sentencia, cuyo análisis nos ocupa, se puede apreciar con claridad cómo la Sala Constitucional del Tribunal Supremo de Justicia ha rebasado con creces los límites que necesariamente debe saber observar una institución que ejerce la jurisdicción constitucional: La Sala sentenciadora no ha tenido en cuenta, en absoluto, la teoría del «self-restraint» tan predicada y admitida por la doctrina constitucionalista cuando se ocupa de este tema ${ }^{24}$.

De este modo la forma de actuación de este órgano no se ha adaptado para nada a las prescripciones constitucionales, puesto que, haciendo caso omiso de que sus competencias están tasadas (art. 336 de la Constitución vigente) ha "creado" una nueva función que no existía y ha invadido la esfera del poder legislativo que es a quien le corresponde en primer lugar interpretar y desarrollar la Constitución. A estos efectos el mismo art. 336, apdo. 11 de la Constitución prescribe que es el legislador el que puede ampliar el campo competencial de la Sala Constitucional. No sólo el legislador, sino también el poder de reforma en cuanto poder constituyente constituido ${ }^{25}$. El procedimiento con que ha actuado se asemeja más a un órgano político que a un órgano jurisdiccional: Porque,

${ }^{23} \mathrm{Al}$ respecto puede consultarse la obra de M. L. BALAGUER CALLEJÓN: La interpretación de la Constitución por la jurisdicción ordinaria, en especial los Capítulos II y III donde se tratan, entre otros temas, como la aplicación e interpretación del Derecho Constitucional y la Constitución y el sistema de fuentes del Derecho. Civitas, Madrid, 1990.

${ }^{24}$ Cfr. J. Pérez RoYo: Tribunal Constitucional..., op. cit. y la abundante bibliografía allí citada. También E. GARCía DE ENTERRía: «La posición jurídica del Tribunal Constitucional...» op. cit., págs. 175 y ss.

${ }^{25}$ Cfr. P. De Vega García: La reforma constitucional..., op. cit. pág. 71 y ss. 
aunque no podamos decir que ha actuado de oficio, sí ha aprovechado una "consulta» efectuada por un ciudadano para crear una "acción o recurso autónomo de interpretación» ampliando la legitimación -que debe ser restringida- y creando un procedimiento "ad hoc» para la resolución de estos casos; procedimiento de jurisdicción constitucional en el que no observamos una actuación propia de estos casos pues, ni su decisión se refiere a un caso individual y concreto, ni el procedimiento por el cual la Sala Constitucional ha adquirido la información, la ha procesado y la ha traducido en una sentencia se adapta a los cánones al uso, porque se aprecia con claridad que ha condicionado la voluntad de otros órganos del Estado, especialmente la del legislador sustituyéndola positivamente ${ }^{26}$.

El problema es más serio de lo que puede aparentar porque nos remonta a los orígenes de la justicia Constitucional en Europa, en el primer tercio del siglo $\mathrm{XX}$, donde en medio de la polémica sustentada entre Kelsen y Schmitt siempre se terminaba debatiendo sobre el tema de ¿quién controla al controlador?27 A nadie se le escapa que al tratarse de órganos que son únicos en su orden y cuyos pronunciamientos tienen eficacia vinculante en todo el territorio nacional tienen también la última palabra en los asuntos que se someten a su consideración. Por ello se ha insistido tanto en el «self-restraint» del órgano titular del control de constitucionalidad. Autolimitación que por otra parte tampoco puede tener ninguna sanción jurídicamente organizada porque, en este caso la Sala Constitucional, es la última instancia ${ }^{28}$. Para resolver el problema no se nos ocurren soluciones definitivas; apostamos por un correcto entendimiento de la Sala Constitucional de cuáles son sus funciones y en base a ello dejar de admitir a trámite "cuestiones abstractas de interpretación constitucional» para las que, aunque en la sentencia así lo mantiene, no tiene competencias. De no seguir esta vía caben peligros mayores y es que, el legislador orgánico, en su día, cuando desarrolle el Título VIII de la Constitución siguiendo los dictados de la Sala incluya entre el marco competencial esta nueva función que dicho órgano se ha autoatribuido.

De lo contrario, si la Sala siguiese en sus funciones ejerciendo competencias «políticas» como es la interpretación «in abstracto» de la norma constitucional sólo queda, en pro de un funcionamiento correcto del sistema desde un punto de vista jurídico, la actuación del poder constituyente originario, al cual la Sala Constitucional no puede controlar. Si el pueblo, como titular del poder consti-

${ }^{26}$ Cfr. H. KelSEN: «Wesen und Entwicklung der Staatsgerichtsbarkeit» en P. HÄBERLE, op. cit. pág. 82. También H. P. SCHNEIDER: «Jurisdicción Constitucional...», op. cit. pág. 40.

${ }_{27}$ Cfr. H. Kelsen: La giustizia costituzionale, Giuffré, Milano, 1981, págs. 299-291.

${ }^{28}$ Cfr. en este sentido J. Pérez Royo: Tribunal Constitucional..., op. cit., pág. 23 
tuyente entendiese que la Sala ha llegado a conclusiones inaceptables, puede poner en marcha el poder de revisión constitucional y definir la naturaleza y funciones de la Sala en el sentido que el constituyente decida, según su libertad incondicionada ${ }^{29}$.

B/ La interpretación constitucional es necesaria y se plantea como problema cuando se tiene que dar respuesta a alguna cuestión constitucional que la Constitución no permite resolver de forma concluyente, porque, es evidente que donde no se suscitan dudas no se interpreta. La función de la interpretación en encontrar el resultado constitucionalmente correcto, mediante un procedimiento racional y controlable que cree certeza jurídica. No se trata de la simple decisión por la decisión ${ }^{30}$.

Dadas las peculiaridades jurídicas de las normas constitucionales ${ }^{31}$, las tradicionales reglas de interpretación resultan insuficientes para dar respuesta al complejo problema que hoy plantea la interpretación constitucional que supone «concretizar» lo que no aparece de forma clara como contenido de la Constitución. De este modo esa interpretación tiene carácter creativo, porque el contenido de la norma interpretada sólo queda completo con su interpretación ${ }^{32}$.

Ahora bien, la concretización presupone la comprensión del contenido de la norma que se va a concretizar, la cual no se puede desvincular ni de la precomprensión del intérprete ni del problema concreto a resolver. El intérprete no puede captar el contenido de la norma situándose fuera de la existencia histórica sino únicamente desde la concreta situación histórica en la que se encuentra. Puesto que "comprender» $\mathrm{y}$ "concretizar» sólo es posible respecto a un problema concreto, el intérprete tiene que poner en relación con dicho problema la norma que pretende entender si quiere determinar su contenido correcto en el momento de la interpretación. Esa determinación y la aplicación de la norma al caso concreto, constituyen un proceso único pues no existe interpretación constitucional desvinculada de los problemas concretos ${ }^{33}$.

${ }^{29}$ Cfr. E. García de ENTERría: «La posición jurídica...», op. cit., págs. 200 y ss.

30 Cfr. K. STERn: Das Staatsrecht der Bundesrepublik Deutschland, Vol I, 1977, págs. 33 y ss.

31 Sobre este tema es obligada la consulta del trabajo de A. NIETO: «Peculiaridades jurídicas de la norma constitucional», Revista de Administración Pública, no 100-102, Madrid 1983, Vol I, págs. 37 y ss.

32 Por eso va más allá de los elementos de interpretación de la ley, ya clásicos, formulados por SAVIGNY (gramatical, lógico, histórico y sistemático). Cfr. sobre este punto A. HollerbaCH: "Auflösung der rechtsstaatlichen Verfassung?», Archiv des öffentlichen Rechts, 85 (1960), págs. 258 y ss.

33 Cfr. K. Hesse: Escritos de derecho constitucional, Centro de Estudios Constitucionales, Madrid, 1983, págs. 43 y ss. 
La interpretación de la norma de cuya concretización se trata depende de la precomprensión del intérprete y del problema concreto que en cada caso se quiere resolver, por ello, no puede haber un método de interpretación autónomo, desvinculado de estos factores y formulado positivamente. Respecto al tema que nos ocupa, queremos resaltar que uno de los principios de interpretación constitucional es el criterio de la «corrección funcional» que se justifica porque, si la Constitución regula de una forma determinada la naturaleza y funciones de los órganos estatales, el órgano encargado de la interpretación debe mantenerse en el marco de las funciones que le han sido encomendadas. Este órgano no debe modificar la distribución de las funciones a través de los métodos y resultados de dicha interpretación. Esto se aplica especialmente a las relaciones entre el legislador y el órgano encargado de ser el último intérprete de la Constitución (en este caso la Sala Constitucional) puesto que, a la Sala Constitucional sólo le corresponde frente al legislador una función de control y le está prohibida una interpretación que conlleva a restringir la libertad del legislador más allá de los límites establecidos por la propia Constitución o, incluso, como ha sucedido en esta sentencia a una conformación llevada a cabo por la propia Sala Constitucional ${ }^{34}$.

El intérprete de la Constitución no actúa con plena libertad: se halla vinculado a algo previamente establecido. Por eso los límites de la interpretación se sitúan allí donde no existe algo establecido de forma vinculante por la Constitución, donde acaban las posibilidades de una comprensión lógica del texto de la norma o donde una determinada solución se encuentra en cara contradicción con el texto de la norma. La interpretación puede originar un cambio constitucional pero, lo que está excluido es la desviación del texto en un caso concreto (quebrantamiento constitucional) y la reforma de la Constitución por medio de la interpretación. En aquellos casos en los que el intérprete se impone a la Constitución (como ha hecho la Sala Constitucional en la Sentencia 1077) deja de interpretarla para cambiarla o quebrantarla. Cualquiera de las dos conductas le están prohibidas desde la Teoría del Derecho Constitucional ${ }^{35}$ y cualquier interpretación que parta del carácter de norma suprema de la Constitución, obliga a entender que ésta constituye el límite infranqueable de su actuación.

34 Sobre este tema puede consultarse de forma detallada H. EHMKE: «Prinzipien der Verfassungsinterpretation» en Veröffentlichungen der Vereinigung der deutschen staatsrechtslehrer, 20 (1963), pág. 73. También K. HeSSE: Escritos... op. cit. págs. 49 y ss.

35 Cfr. al respecto F. MÜlLER: Normstruktur und Normativität. Zum Verhältnis von Recht und Wirklichkeit in der juristischen Hermeneutik, entwickelt in der juristischen Hermeneutik, entwickelt an Fragen der Verfassungsinterpretation, 1966. También M. KRIELE: Theorie der Rechtsgewinnung, 2a ed., 1976. Y, P. DE VEGA: La reforma constitucional... op. cit, pág. 170 y ss. En una línea semejante K. Hesse: Escritos de Derecho Constitucional, op. cit. pág. 51 y ss. 


\title{
TITLE
}

\section{CONSIDERATIONS ON THE RESOURCE OF CONSTITU- TIONAL INTERPRETATION IN VENEZUELA}

\section{RESUMEN}

La Constitución de la Republica Bolivariana de Venezuela, del año 1999, reconoció su carácter de norma suprema y creó una Sala Constitucional en el Tribunal Supremo de Justicia con el objeto de que ejerza la jurisdicción constitucional en un modelo donde conviven elementos del modelo concentrado y del modelo difuso de defensa de la Constitución.

El citado órgano jurisdiccional, en la sentencia 1077, creó una nueva competencia que denominó «recurso autónomo de interpretación de la Constitución", mediante el cual interpreta de forma abstracta las normas constitucionales al margen de problemas concretos que vinculen dicha interpretación. La Sala Constitucional demuestra en su interpretación jurídica que no le ha sido atribuida una competencia como la ejercitada y funda su actuación en la existencia en el ámbito de la jurisdicción ordinaria de un recurso de interpretación de leyes (art. 266 de la $\mathrm{CB}$ ) que, operando "per saltum», hace aconsejable la existencia de un recurso de interpretación constitucional (art. 335 de la C.B). La sentencia en cuestión nos aproxima al estudio de los principales problemas que actualmente tiene planteados la interpretación de la Constitución y al tema de los límites a la actuación del supremo intérprete constitucional, quien puede invadir con sus resoluciones el ámbito de actuación de los poderes constituidos.

\begin{abstract}
The 1999 Constitution of the Bolivarian Republic of Venezuela recognized his character of supreme rule and created a Constitutional Division within the Supreme Court of Justice, whose function is to exert the constitutional jurisdiction inside a scheme that combines elements from both the concentrated and the diffuse models of defense of the Constitution.

The above mentioned constitutional organ, in its 1077 sentence, created a new competence named «autonomous appeal of constitutional interpretation", by which it interprets in an abstract way the constitutional rules away from specific problems which may bind such interpretation. The Constitutional Division shows in its juridical interpretation that it has not actually been attributed with the competence it exerts, and its acting is funded in the existence of an appeal for the
\end{abstract}


interpretation of laws (article 266 of the Constitution), which, operating "per saltum", shows that the existence of a constitutional interpretation appeal would be advisable (article 335 of the Constitution). The mentioned sentence brings us closer to the study of the main problems that exist nowadays in the field of the interpretation of the Constitution, and also to the issue of the limits of the actuation of the supreme constitutional interpreter, who can invade with its resolutions the field of action of the constituted powers.

\section{PALABRAS CLAVE}

Constitución, supremo intérprete, recurso de interpretación, Sala Constitucional, límites, sentencia.

\section{KEY WORDS}

Constitution, supreme interpreter, interpretation appeal, Constitutional Division, limits, sentence. 